\title{
Cardiovascular diseases in youth patients with glucose metabolism impairment
}

\author{
Aleksandra Pilśniak', Artur Chwalba' ${ }^{2}$ Ewa Otto-Buczkowska ${ }^{3}$ \\ 'Inpatient Department of Radiation and Clinical Oncology, Maria Skłodowska-Curie Institute - Oncology Center, Gliwice, Poland \\ ${ }^{2}$ Department of Pharmacology, Medical University of Silesia, Zabrze, Poland \\ ${ }^{3}$ Medical Specialist Centre in Gliwice, Gliwice, Poland
}

\begin{abstract}
Glucose metabolism disorders in adolescent patients have a diverse background. The most common cause is type 1 diabetes. Persistently elevated blood glucose initiates many processes that lead to blood vessel and nerve damage. Early detection and treatment of these abnormalities can help prevent the development of many complications.

Key words: impairments of carbohydrates metabolism; insulin resistance; hyperinsulinemia; cardiovascular disease; cardiomyopathy; macroangiopathy; blood pressure monitoring

Arterial Hypertens. 2021, vol. 25, no. 2, pages: 63-68

DOI: 10.5603/AH.a2020.0016
\end{abstract}

\section{Introduction}

Carbohydrate metabolism disorders of varying nature can also be found in adolescent patients. It is known that any impairment of carbohydrate metabolism, accompanied by hyperglycemia, regardless of etiology, leads to chronic complications. Therefore, early recognition of elevated blood glucose levels and rapid normalization is very important. The underlying causes of hyperglycemia can be very diverse; excessive amounts of glucose may also stem from conditions other than type 1 diabetes. Currently, much attention is devoted to cardiovascular diseases underlying hyperglycemia; what is more, these may already occur in young patients. The results of many studies indicate that the processes leading to the occurrence of cardiovascular diseases in patients with type 1 diabetes begin already in childhood and adolescence $[1,2]$. Long-term studies indicate that in children and adolescents who exhibit risk factors, the risk of developing macroangiopathy is significantly higher than in the general population [3, 4]. Graves end Donaghue has recently provided a comprehensive discussion of this issue [5]. The authors believe that subclinical cardiovascular diseases may develop already in the first decade after diagnosis of type 1 diabetes. Therefore, blood pressure and dyslipidemia screening should be initiated in children from 11 years of age. In addition, with a family history of hypercholesterolemia, screening should be carried out as early as 2 years of age. It is assumed that the frequency of cardiovascular risk factors is high in youth with type 1 diabetes and is associated with diabetes duration, obesity, and metabolic control [6].

\section{Risk factors for microangiopathy in diabetic patients at developmental age}

The recommendations of the International Society for Pediatric and Adolescent Diabetes (ISPAD) re-

Address for correspondence: Aleksandra Pilśniak, Inpatient Department of Radiation and Clinical Oncology, Maria Skłodowska-Curie Institute
— Oncology Center, Wybrzeże Armii Krajowej 15, 44-102 Gliwice, Poland; e-mail: dudek.ola@op.pl

This article is available in open access under Creative Common Attribution-Non-Commercial-No Derivatives 4.0 International (CC BY-NC-ND 4.0) license, allowing to download articles and share them with others as long as they credit the authors and the publisher, but without permission to change them in any way or use them commercially 
garding the prevention of vascular complications indicate the existence of documented risk factors for macroangiopathy in children and adolescents. These include hyperglycemia, hypertension, and lipid disorders $[7,8]$. Other authors add to this list the presence of a cardiovascular disease and/or lipid disorders in the patient's family [9]. Endothelial dysfunction is also important in the development of chronic complications of diabetes with microangiopathy [10]. Endothelial progenitor cell (EPC) dysfunction may underlie the mechanisms involved in the development of vascular complications in diabetic patients [11].

\section{Hyperglycemia}

Hyperglycemia is a recognized risk factor for the development of microangiopathy in type 1 diabetes. Inadequate metabolic control of diabetes is also a risk factor for macroangiopathy in adult patients with type 1 diabetes. The importance of hyperglycemia in the development of macroangiopathy in type 1 diabetes has been confirmed by several publications.

Persistent hyperglycemia leads to:

- the activation of nonenzymatic glycation of proteins - advanced glycation end-products (AGEs) become present in vascular walls in the early stadium of diabetes, resulting in their damage;

- the activation of the sorbitol cycle, a side cycle of glucose metabolism - an increase in glucose concentration in the extracellular compartment causes the activation of aldose reductase, which converts glucose into sorbitol;

- an increase in oxidative stress - due to chronic hyperglycemia.

Chronic hyperglycemia leads to damage to the vascular endothelium, which leads to the development of atherosclerosis [12]. Glycemic variability in the pathogenesis of diabetic cardiovascular complications is particularly dangerous [13-16]. Another component of the atherosclerotic process is the impairment of arteriolar vasodilation and the increased stiffness of arterioles. Genetic factors also play an important role in the pathogenesis of late complications of immune-mediated diabetes [17]. It has been established that endothelial dysfunction in patients with type 1 diabetes is independent in comparison with classic risk factors. It may be influenced by the haptoglobin $(\mathrm{Hp})$ genotype [18]. Hyperlipidemia is an important risk factor for angiopathy. Lipid profile changes are risk factors for changes in the cardiovascular system. Lipid disorders are closely associated with type 2 diabetes, but they also occur in a significant proportion of patients with type 1 diabetes, including patients at the development age. As recom- mended by the International Society for Pediatric and Adolescent Diabetes (ISPAD) and the American Diabetes Association (ADA), hyperlipidemia screenings should be performed on all adolescents with type 1 diabetes $[7,19,20]$. If the family of the sick child has cardiovascular disease or hypercholesterolemia, or family history is unknown, lipid assessment should be carried out from the age of two. Insulin resistance is one of the risk factors for changes in the cardiovascular system $[21,22]$.

\section{Hypertension}

The risk factor for micro- and macroangiopathy in diabetes is hypertension. Its development often precedes the diagnosis of diabetes. Patients with type 1 diabetes are more likely to have disturbances in their diurnal blood pressure variability more often than non-diabetic patients, consisting in the lack of the night-time drop in arterial pressure, which is, physiologically, $15-20 \%$ of the daytime pressure. In these patients, despite higher blood pressure at night, blood pressure measured during the day might not deviate from normal values. Diagnosis of disturbances in the circadian blood pressure cycle is possible only through 24-hour blood pressure monitoring. The risk of vascular complications in a group of patients with an abnormal circadian rhythm of blood pressure is significantly higher than in those with a normal circadian rhythm of blood pressure [23-25].

\section{Diabetes and the autonomic system of the heart}

At developmental age, type 1 diabetes mellitus is the most common cause of the glucose tolerance disorder. Type 1 diabetes causes changes in the autonomic system of the heart. Subclinical autonomic neuropathy has already been reported in children. It was found that autonomic dysfunction is associated both with the duration and an inadequate metabolic control of the disease [26]. Sympathetic heart dysfunction in diabetes is caused by metabolic, vascular, as well as immunological factors. Autoantibodies against sympathetic ganglia have been demonstrated in patients with type 1 diabetes. These antibodies are specific for diabetic cardioneuropathy and occur independently of antibodies directed against $\beta$ cells. Antibodies directed against sympathetic post-ganglionic neurons cause local damage and deterioration of nerve cell function in patients with type 1 diabetes $[27,28]$. It has been shown that hypertension may be the first clinical sign of autonomic neuropathy. The 
association of the cardiac autonomic neuropathy/ hypertension profile with vascular complications is consistent with a deleterious effect on vascular hemodynamics and structure, additional to the effects of hypertension [29-31].

\section{Insulin resistance}

Insulin resistance is another causative factor of cardiovascular complications, mainly macroangiopathy. It is found more often in juvenile patients with type 1 diabetes [32, 33].

\section{Diagnostics}

With the increase in the frequency of chronic complications in diabetes, more and more importance is attached to diagnostic methods to adopt an appropriate therapeutic strategy during the period of reversible vascular changes. Endothelial dysfunction defined as an abnormal vascular response to endothelium-dependent vasodilators can be assessed by non-invasive ultrasound methods, while endothelial activation is detected by testing the concentration of substances produced by the endothelium in the blood serum. Jenkins et al draws attention to the need to improve diagnostic methods for measuring arterial intima-media thickness, coronary artery calcification and angiography, and other methods like intravascular ultrasound and optical coherence tomography [34]. The same authors also emphasize the need to improve novel clinical, biochemical and molecular tests; vascular MRI and molecular imaging.

\section{Markers of cardiovascular damage}

Non-invasive methods of assessing cardiovascular damage include:

- flow-mediated dilation indicator (FMD);

- ultrasound assessment of carotid, abdominal and femoral arteries — intimal plus medial thickness (IMT), and aortic intimal plus medial thickness (aIMT);

- echocardiographic tests (assessment of left ventricular systolic and diastolic function, assessment of left ventricular mass);

- 24-hour monitoring of cardiac function using the Holter method;

- 24-hour ambulatory blood pressure monitoring (ABPM);
- assessment of microalbuminuria;

- capillaroscopy;

- electron beam tomography (EBT).

Biochemical markers of endothelial damage are:

- adhesion molecules: intercellular adhesion molecule 1 (ICAM), vascular cell adhesion molecule 1 (VCAM), thrombomodulin (TM), integrins, selectins;

- inflammatory cytokines: interleukins 1, 2, 6 and 8 (IL-1, IL-2, IL-6, IL-8), tumor necrosis factor (TNF), monocyte chemoattractant protein 1 (MCP-1);

- homocysteine;

- C-reactive protein (CRP).

Changes in biomarker levels indicate the involvement of vascular endothelial dysfunction and inflammation in the development of premature arterial stiffening and hypertension in patients with type 1 diabetes [35].

Furthermore, these patients show significantly higher concentrations of chosen markers of endothelial dysfunction compared to controls [36, 37].

\section{Flow-mediated dilation}

Flow-mediated dilation (FMD) assessed in the brachial artery has been shown to correlate with changes in coronary endothelial function as well as angiographic studies of these vessels, which has been confirmed by autopsy [3, 38].

\section{Intima-media thickness}

Intima-media thickness (IMT) is used as indicator of early lesions of atherosclerosis. The evaluation of IMT in the carotid arteries of patients with type 1 diabetes has shown a more advanced degree of atherosclerosis than healthy controls [39]. Other authors believe that aortic IMT (and, to a lesser degree, femoral IMT) is more sensitive than carotid and brachial IMT for detecting early macrovascular changes in pediatric type 1 diabetic patients [40].

\section{Left ventricular geometry}

Significant changes in left ventricular geometry, diastolic function and energy metabolism in patients with type 1 diabetes are all associated with overt microvascular complications [41]. The disturbance of left ventricular systolic and diastolic parameters is a preview of the development of diabetic cardiomy- 
opathy. Left ventricular hypertrophy is thought to be a preclinical manifestation of hypertension, and a risk factor for cardiovascular complications.

\section{Electron beam tomography and single-photon emission computed tomography}

Based on electron beam tomography (EBT), the degree of coronary artery calcification - an early marker of cardiovascular disease - can be assessed [42]. Coronary calcification is an active process which is strongly associated with atherosclerosis. This method is useful in examining patients over 30 years of age. The single-photon emission computed tomography (SPECT) method is for evaluating myocardial perfusion imaging (MPI) [43].

\section{Biochemical markers of endothelial damage}

As regards biochemical markers of endothelial damage in type 1 diabetes, consideration should be given to assessing the lipoprotein profile, coagulation and fibrinolysis parameters, homocysteine levels, and changes occurring during the activation of endothelial cells. It has been shown that endothelial cells are activated and chronic vasculitis occurs many years before a symptomatic coronary heart disease [44-47].

\section{Conclusions}

To conclude, it should be emphasized that children with type 1 diabetes may develop subclinical cardiovascular complications of both micro- and macroangiopathy. Their early diagnosis is very important; hence, the recommendation to carry out screening tests from ten years of age, and in those who are particularly at risk from two years of age. Already at the age of ten, such measures as the assessment of microalbuminuria and blood pressure, ultrasound of arteries, ophthalmological tests, echocardiographic tests, and capillaroscopic tests are recommended. For specific indications, tests should be performed to detect early markers of cardiovascular diseases. Early diagnosis of risk factors for complications is important in the prevention or deferral of complications in patients with type 1 diabetes [48, 49, 50, 51]. Many authors emphasize the importance of early identification and treatment of cardiovascular disease risk factors, as recommended in multiple guidelines [52].

\section{References}

1. Sun D, Li X, Heianza Y, et al. Childhood cardiovascular risk factors and carotid vascular changes in adulthood: the Bogalusa Heart Study. JAMA. 2003; 290(17): 2271-2276, doi: 10.1001/ jama.290.17.2271, indexed in Pubmed: 14600185.

2. Raitakari OT, Juonala $M$, Kähönen $M$, et al. Cardiovascular risk factors in childhood and carotid artery intima-media thickness in adulthood: the Cardiovascular Risk in Young Finns Study. JAMA. 2003; 290(17): 2277-2283, doi: 10.1001/jama.290.17.2277, indexed in Pubmed: 14600186.

3. Babar GS, Zidan H, Widlansky ME, et al. Impaired endothelial function in preadolescent children with type 1 diabetes. Diabetes Care. 2011; 34(3): 681-685, doi: 10.2337/dc10-2134, indexed in Pubmed: 21289230.

4. Rodriguez BL, Fujimoto WY, Mayer-Davis EJ, et al. Prevalence of cardiovascular disease risk factors in U.S. children and adolescents with diabetes: the SEARCH for diabetes in youth study. Diabetes Care. 2006; 29(8): 1891-1896, doi: 10.2337/dc06-0310, indexed in Pubmed: 16873798.

5. Graves LE, Donaghue KC. Management of diabetes complications in youth. Ther Adv Endocrinol Metab. 2019; 10: 2042018819863226, doi: 10.1177/2042018819863226, indexed in Pubmed: 31384418.

6. Stankute I, Dobrovolskiene R, Danyte E, et al. Factors Affecting Cardiovascular Risk in Children, Adolescents, and Young Adults with Type 1 Diabetes. J Diabetes Res. 2019; 2019: 1-10, doi: 10.1155/2019/9134280, indexed in Pubmed: 31223626.

7. Donaghue KC, Wadwa RP, Dimeglio LA, et al. International Society for Pediatric and Adolescent Diabetes. ISPAD Clinical Practice Consensus Guidelines 2014. Microvascular and macrovascular complications in children and adolescents. Pediatr Diabetes. 2014; 15 Suppl 20: 257-269, doi: 10.1111/pedi.12180, indexed in Pubmed: 25182318.

8. Wadwa RP. Cardiovascular disease risk in youth with diabetes mellitus. Rev Endocr Metab Disord. 2006; 7(3): 197-204, doi: 10.1007/s11154-006-9016-y, indexed in Pubmed: 17160723.

9. Glowinska B, Urban M, Koput A. Cardiovascular risk factors in children with obesity, hypertension and diabetes: lipoprotein(a) levels and body mass index correlate with family history of cardiovascular disease. Eur J Pediatr. 2002; 161(10): 511-518, doi: 10.1007/s00431-002-1040-7, indexed in Pubmed: 12297895.

10. Stettler C, Allemann S, Jüni P, et al. Glycemic control and macrovascular disease in types 1 and 2 diabetes mellitus: Meta-analysis of randomized trials. Am Heart J. 2006; 152(1): 27-38, doi: 10.1016/j.ahj.2005.09.015, indexed in Pubmed: 16824829.

11. Głowińska-Olszewska B, Luczyński W, Bossowski A. [Endothelial progenitor cells as a new marker of endothelial function with respect to risk of cardiovascular disorders]. Postepy Hig Med Dosw (Online). 2011; 65: 8-15, doi: 10.5604/17322693.931086, indexed in Pubmed: 21357990.

12. Longo M, Scappaticcio L, Bellastella G, et al. METRO Study Group. Alterations in the Levels of Circulating and Endothelial Progenitor Cells Levels in Young Adults with Type 1 Diabetes: A 2-Year Follow-Up from the Observational METRO Study. Diabetes Metab Syndr Obes. 2020; 13: 777-784, doi: $10.2147 /$ DMSO.S238588, indexed in Pubmed: 32256094.

13. Babar G, Clements M, Dai H, et al. Assessment of biomarkers of inflammation and premature atherosclerosis in adolescents with type-1 diabetes mellitus. J Pediatr Endocrinol Metab. 2019; 32(2): 109-113, doi: 10.1515/jpem-2018-0192, indexed in Pubmed: 30710485.

14. Gorst C, Kwok CS, Aslam S, et al. Long-term Glycemic Variability and Risk of Adverse Outcomes: A Systematic Review and Meta-analysis. Diabetes Care. 2015; 38(12): 2354-2369, doi: 10.2337/dc15-1188, indexed in Pubmed: 26604281. 
15. Nusca A, Tuccinardi D, Albano M, et al. Glycemic variability in the development of cardiovascular complications in diabetes. Diabetes Metab Res Rev. 2018; 34(8): e3047, doi: 10.1002/ dmrr.3047, indexed in Pubmed: 30028067.

16. Xia J, Yin C. Glucose Variability and Coronary Artery Disease. Heart Lung Circ. 2019; 28(4): 553-559, doi: 10.1016/j. hlc.2018.10.019, indexed in Pubmed: 30527849.

17. Costantino S, Ambrosini S, Paneni F. The epigenetic landscape in the cardiovascular complications of diabetes. J Endocrinol Invest. 2019; 42(5): 505-511, doi: 10.1007/s40618-018-0956-3, indexed in Pubmed: 30291588.

18. Llauradó G, Gutiérrez C, Giménez-Palop O, et al. Haptoglobin genotype is associated with increased endothelial dysfunction serum markers in type 1 diabetes. Eur J Clin Invest. 2015; 45(9): 932-939, doi: 10.1111/eci.12487, indexed in Pubmed: 26122942.

19. Koschinsky ML, Marcovina SM. The relationship between lipoprotein(a) and the complications of diabetes mellitus. Acta Diabetol. 2003; 40(2): 65-76, doi: 10.1007/s005920300007, indexed in Pubmed: 12861403.

20. Siminerio LM, Albanese-O'Neill A, Chiang JL, et al. American Diabetes Association. Care of young children with diabetes in the child care setting: a position statement of the American Diabetes Association. Diabetes Care. 2014; 37(10): 2834-2842, doi: 10.2337/dc14-1676, indexed in Pubmed: 25249671.

21. Hsueh WA, Lyon CJ, Quiñones MJ. Insulin resistance and the endothelium. Am J Med. 2004; 117(2): 109-117, doi: 10.1016/j. amimed.2004.02.042, indexed in Pubmed: 15234647.

22. Lee Y, Chakraborty S, Meininger CJ, et al. Insulin resistance disrupts cell integrity, mitochondrial function, and inflammatory signaling in lymphatic endothelium. Microcirculation. 2018; 25(7): e12492, doi: 10.1111/micc.12492, indexed in Pubmed: 30025187.

23. Czupryniak L, Saryusz-Wolska M, Pawlowski M, et al. Elevated systolic blood pressure is present in almost all individuals with newly diagnosed diabetes. J Hum Hypertens. 2006; 20(3): 231-233, doi: 10.1038/sj.jhh.1001962, indexed in Pubmed: 16319907.

24. Krishnan S, Short KR. Prevalence and significance of cardiometabolic risk factors in children with type 1 diabetes. J Cardiometab Syndr. 2009; 4(1): 50-56, doi: 10.1111/j.15594572.2008.00034.x, indexed in Pubmed: 19245517.

25. Mateo-Gavira I, Vílchez-López FJ, García-Palacios MV, et al. Early blood pressure alterations are associated with pro-inflammatory markers in type 1 diabetes mellitus. J Hum Hypertens. 2017; 31(2): 151-156, doi: 10.1038/jhh.2016.56, indexed in Pubmed: 27535123.

26. Chessa M, Butera G, Lanza GA, et al. Role of heart rate variability in the early diagnosis of diabetic autonomic neuropathy in children. Herz. 2002; 27(8): 785-790, doi: 10.1007/s00059002-2340-4, indexed in Pubmed: 12574897.

27. Kowalewski MA, Urban M. Short- and long-term reproducibility of autonomic measures in supine and standing positions. Clin Sci (Lond). 2004; 106(1): 61-66, doi: 10.1042/CS20030119, indexed in Pubmed: 12889989.

28. Pop-Busui R. Cardiac autonomic neuropathy in diabetes: a clinical perspective. Diabetes Care. 2010; 33(2): 434-441, doi: 10.2337/dc09-1294, indexed in Pubmed: 20103559.

29. Ayad F, Belhadj M, Pariés J, et al. Association between cardiac autonomic neuropathy and hypertension and its potential influence on diabetic complications. Diabet Med. 2010; 27(7): 804-811, doi: 10.1111/j.1464-5491.2010.03027.x, indexed in Pubmed: 20636962.

30. Karavanaki K, Baum JD. Coexistence of impaired indices of autonomic neuropathy and diabetic nephropathy in a cohort of children with type 1 diabetes mellitus. J Pediatr Endocrinol Metab. 2003; 16(1): 79-90, doi: 10.1515/jpem.2003.16.1.79, indexed in Pubmed: 12585344.

31. Pietrzak I, Szadkowska A, Czerniawska E, et al. [Prehypertension risk factors in children and adolescents with type 1 diabetes]. Przegl Lek. 2006; 63 Suppl 3: 111-114, indexed in Pubmed: 16898504

32. Pietrzak I, Mianowska B, Gadzicka A, et al. Blood pressure in children and adolescents with type 1 diabetes mellitus--the influence of body mass index and fat mass. Pediatr Endocrinol Diabetes Metab. 2009; 15(4): 240-245, indexed in Pubmed: 20455418.

33. Specht BJ, Wadwa RP, Snell-Bergeon JK, et al. Estimated insulin sensitivity and cardiovascular disease risk factors in adolescents with and without type 1 diabetes. J Pediatr. 2013; 162(2): 297-301, doi: 10.1016/j.jpeds.2012.07.036, indexed in Pubmed: 22921593.

34. Jenkins A, Januszewski A, O'Neal D. The early detection of atherosclerosis in type 1 diabetes: why, how and what to do about it. Cardiovasc Endocrinol Metab. 2019; 8(1): 14-27, doi: 10.1097/ XCE.0000000000000169, indexed in Pubmed: 31646294.

35. Ferreira I, Hovind P, Schalkwijk CG, et al. Biomarkers of inflammation and endothelial dysfunction as predictors of pulse pressure and incident hypertension in type 1 diabetes: a 20 year life-course study in an inception cohort. Diabetologia. 2018; 61(1): 231-241, doi: 10.1007/s00125-017-4470-5, indexed in Pubmed: 29101422

36. Machnica L, Deja G, Polanska J, et al. Blood pressure disturbances and endothelial dysfunction markers in children and adolescents with type 1 diabetes. Atherosclerosis. 2014; 237(1): 129-134, doi: 10.1016/j.atherosclerosis.2014.09.006, indexed in Pubmed: 25238220.

37. Sochett E, Noone D, Grattan M, et al. Relationship between serum inflammatory markers and vascular function in a cohort of adolescents with type 1 diabetes. Cytokine. 2017; 99: 233-239, doi: 10.1016/j.cyto.2017.07.013, indexed in Pubmed: 28760408.

38. Järvisalo MJ, Lehtimäki T, Raitakari OT. Determinants of arterial nitrate-mediated dilatation in children: role of oxidized low-density lipoprotein, endothelial function, and carotid intima-media thickness. Circulation. 2004; 109(23): 2885-2889, doi: 10.1161/01.CIR.0000129304.98566.D8, indexed in Pubmed: 15159289

39. Tołwińska J, Głowińska-Olszewska B, Urban M, et al. [Ultrasonographic evaluation of selected parameters of the endothelial function in brachial arteries and IMT measurements in carotid arteries in children with diabetes type 1 using personal insulin pumps - preliminary report]. Pediatr Endocrinol Diabetes Metab. 2006; 12(3): 200-204, indexed in Pubmed: 17020656.

40. Lilje C, Cronan JC, Schwartzenburg EJ, et al. Intima-media thickness at different arterial segments in pediatric type 1 diabetes patients and its relationship with advanced glycation end products. Pediatr Diabetes. 2018; 19(3): 450-456, doi: 10.1111/ pedi.12557, indexed in Pubmed: 28664608

41. Perseghin G, Lattuada G, De Cobelli F, et al. Left ventricular function and energy homeostasis in patients with type 1 diabetes with and without microvascular complications. Int J Cardiol. 2012; 154(2): 111-115, doi: 10.1016/j.ijcard.2010.09.010, indexed in Pubmed: 20926147.

42. Snell-Bergeon JK, Budoff MJ, Hokanson JE. Vascular calcification in diabetes: mechanisms and implications. Curr Diab Rep. 2013; 13(3): 391-402, doi: 10.1007/s11892-013-0379-7, indexed in Pubmed: 23526400

43. de Graaf MA, Roos CJ, Mansveld JM, et al. Changes in ischaemia as assessed with single-photon emission computed tomography myocardial perfusion imaging in high-risk patients with diabetes without cardiac symptoms: relation with coronary atherosclerosis on computed tomography coronary angiography. Eur Heart J Cardiovasc Imaging. 2015; 16(8): 863-870, doi: 10.1093/ehjci/ jev003, indexed in Pubmed: 25680384.

44. Głowińska B, Urban M, Peczyńska J, et al. [Selected adhesion molecules: sICAM-1 and sVCAM-1 as markers of endothelial dysfunction in diabetic children and adolescence]. Pol Merkur Lekarski. 2003; 14(81): 205-209, indexed in Pubmed: 12914095.

45. Pawłowski P, Urban M, Peczyńska J. [Could the expression of L-selectin be an early marker of arterial hypertension and microangiopathy in the course of type 1 diabetes mellitus in juvenile 
patients?]. Pediatr Endocrinol Diabetes Metab. 2005; 11(3): 147-152, indexed in Pubmed: 16232368.

46. Schram MT, Chaturvedi N, Schalkwijk C, et al. EURODIAB Prospective Complications Study. Vascular risk factors and markers of endothelial function as determinants of inflammatory markers in type 1 diabetes: the EURODIAB Prospective Complications Study. Diabetes Care. 2003; 26(7): 21652173, doi: 10.2337/diacare.26.7.2165, indexed in Pubmed: 12832330

47. Verrotti A, Trotta D, Salladini C, et al. Preventing microvascular diabetic complications in children and adolescents: looking beyond glycaemic control. Expert Opin Pharmacother. 2003; 4(4): 525-532, doi: $10.1517 / 14656566.4 .4 .525$, indexed in Pubmed: 12667115.

48. Demirel F, Tepe D, Kara O, et al. Microvascular complications in adolescents with type 1 diabetes mellitus. J Clin Res Pediatr Endocrinol. 2013; 5(3): 145-149, doi: 10.4274/Jcrpe.994, indexed in Pubmed: 24072081.
49. Dunger DB. Banting Memorial Lecture 2016 Reducing lifetime risk of complications in adolescents with Type 1 diabetes. Diabet Med. 2017; 34(4): 460-466, doi: 10.1111/dme.13299, indexed in Pubmed: 27973749.

50. Fröhlich-Reiterer EE, Huber J, Katz H, et al. [Microvascular and macrovascular complications in children and adolescents with type 1 diabetes mellitus]. Wien Med Wochenschr. 2010; 160(1516): 414-418, doi: 10.1007/s10354-010-0816-z, indexed in Pubmed: 20812053.

51. Snell-Bergeon JK, Nadeau K. Cardiovascular disease risk in young people with type 1 diabetes. J Cardiovasc Transl Res. 2012; 5(4): 446-462, doi: 10.1007/s12265-012-9363-x, indexed in Pubmed: 22528676.

52. Bjornstad P, Donaghue KC, Maahs DM. Macrovascular disease and risk factors in youth with type 1 diabetes: time to be more attentive to treatment? Lancet Diabetes Endocrinol. 2018; 6(10): 809-820, doi: $10.1016 /$ S2213-8587(18)30035-4, indexed in Pubmed: 29475800. 